\title{
UAB
}

Universitat Autònoma

de Barcelona

This is the accepted version of the article:

Unzueta, Ugutz; Céspedes, María Virtudes; Sala, Rita; [et al.]. «Release of targeted protein nanoparticles from functional bacterial amyloids : A death star-like approach». Journal of Controlled Release, Vol. 279 (June 2018), p. 29-39. DOI 10.1016/j.jconrel.2018.04.004

This version is available at https://ddd.uab.cat/record/236692

under the terms of the (c) BY-NC-ND license 


\section{Release of targeted protein nanoparticles from functional bacterial amyloids: $A$ Death Star-like approach}

Authors: Ugutz Unzueta ${ }^{1,2,3+¥}, M^{a}$ Virtudes Cespedes $^{3,4+}$, Rita Sala ${ }^{3,4}$, Patricia Alamo ${ }^{3,4}$, Alejandro Sánchez-Chardi5 ${ }^{5}$, Mireia Pesarrodona1,2,3,2, Laura Sánchez-García ${ }^{1,2,3}$, Olivia Cano-Garrido ${ }^{1,2,3}$, Antonio Villaverde ${ }^{1,2,3}$, Esther Vázquez ${ }^{1,2,3, *}$, Ramón Mangues ${ }^{3,4, *}$, Joaquin Seras-Franzoso ${ }^{1,2,3 *, \pi}$

+ Equally contributed

1 Institute of Biotechnology and Biomedicine, Autonomous University of Barcelona, Bellaterra, 08193 Barcelona, Spain

2 Department of Genetics and Microbiology, Autonomous University of Barcelona, Bellaterra, 08193 Barcelona, Spain

${ }^{3}$ CIBER Bioengineering, Biomaterials and Nanomedicine (CIBER-BBN), Bellaterra, 08193 Barcelona, Spain

${ }^{4}$ Biomedical Research Institute Sant Pau (IIB-SantPau) and Josep Carreras Research Institute, Hospital de la Santa Creu i Sant Pau, 08025 Barcelona, Spain

5 Servei de Microscòpia, Autonomous University of Barcelona, Bellaterra, 08193 Barcelona, Spain

¥ Present address: Biomedical Research Institute Sant Pau (IIB-SantPau), Hospital de la Santa Creu i Sant Pau, 08025 Barcelona, Spain.

$\Omega$ Present address: Institute for Research in Biomedicine (IRB Barcelona), The Barcelona Institute of Science and Technology, Barcelona 08028, Spain.

"Present address: Cibbim-Nanomedicine, Vall d'Hebron Research Institute (VHIR), Hospital Vall d'Hebron, 08035, Barcelona, Spain.

*Corresponding authors: Joaquin Seras-Franzoso, Joaquin.Seras@vhir.org; Ramon Mangues, rmangues@santpau.cat, Esther Vazquez, Esther.Vazquez@uab.es 


\begin{abstract}
:
Sustained release of drug delivery systems (DDS) has the capacity to increase cancer treatment efficiency in terms of drug dosage reduction and subsequent decrease of deleterious side effects. In this regard, many biomaterials are being investigated but none offers morphometric and functional plasticity and versatility comparable to protein-based nanoparticles (pNPs). Here we describe a new DDS by which pNPs fabricated as bacterial inclusion bodies (IB) can be easily isolated, subcutaneously injected and used as reservoirs for the sustained release of targeted pNPs. Our approach combines the high performance of $\mathrm{pNP}$, regarding specific cell targeting and biodistribution with the IB supramolecular organization, stability and cost effectiveness. This renders a platform able to provide a sustained source of CXCR4-targeted pNPs that selectively accumulate in tumor cells in a $\mathrm{CXCR}^{+}$colorectal cancer xenograft model. In addition, the proposed system could be potentially adapted to any other protein construct offering a plethora of possible new therapeutic applications in nanomedicine.
\end{abstract}




\section{Introduction:}

Metastatic dissemination in cancer is a consequence of the highly invasive disease and cannot be solely treated by surgery and radiation. In this regard, co-adjuvant chemotherapy using genotoxic drugs is regularly administered to patients as main systemic therapy [1]. Genotoxic drugs are capable of efficiently inducing cancer cell death but they also affect other fast growing healthy cells such as gastrointestinal tract and bone marrow cells due to their lack of targeting. This renders important deleterious side effects and the subsequent dose limitations. In addition, chemotherapy has failed in the treatment of advanced stages of the disease and tumor resistance is often observed during relapses $[2,3]$. The appearance of nanotechnological approaches coupled with the increasing understanding of disease biology, have prompted an important push on the development of more efficient pharmacological strategies [4].Thus, the available knowledge concerning specific cancer cell receptors and signaling pathways intermediates that are involved in disease progression and spread, provides promising tools to attack the disease in new and more efficient ways [5].

Nanoparticles (NPs) have shown potential to reduce systemic toxicity, by the entrapment of the chemotherapeutic agent as well as by reducing needed drug dosage, due to their ability to accumulate into the tumor through the enhanced permeability and retention effect (EPR [6]). Moreover, the use of nano sized drug delivery systems (DDS) allows the incorporation of targeting ligands to direct these nanoparticles to specific tissues or cells that often increase uptake efficiency, reduce off-target effects and therefore improve their therapeutic benefit [7]. Among the milieu of ongoing biomaterials for DDS fabrication, protein based approaches result highly appealing. In particular, self-assembled protein nanoparticles (pNPs) can represent suitable nanosized carriers due to their high biocompatibility and functional plasticity. Their protein nature permits to incorporate, by regular genetic engineering, uncountable combinations of motifs and domains that respond to specific pharmacological needs. In this regard, recent studies have shown the generation of self-assembling protein NPs (pNPs) able to target CXCR4 [8], CD44 [9], LDLR [10] and EGFR [11] among others. In these cases the ligands T22 (CXCR4), R9 (CXCR4), A5 (CD44) and Seq-1 (LDLR) were combined with a GFP scaffold for traceability while specific Anti-EGFR repebody fused to the cytolytic domain Apoptin was employed as a proof of concept for pNPs with therapeutic activity. Particularly interesting for our study are the T22 and R9 peptides. These ligands, with a high specificity for 
CXCR4 receptor [12,13,14], overexpressed in metastatic colorectal cancer [15,16], have been successfully employed to direct and increase pNP cell penetration in CXCR4 positive tumor cells. Also, T22 and R9 are efficient architectonic tags that upon incorporation in the amino terminal of the protein and in combination with a carboxy terminal poly-His tag, induce the self-assembling of GFP into regular sized nanoparticles [17]. In this context, T22-empowered protein nanoparticles (T22-GFP-H6) have shown selective biodistribution and accumulation into the primary tumor as well as in all the macro and micro metastatic foci upon intravenous (i.v.) administration in an orthotopic colorectal cancer mouse model in absence of any off-target accumulation and toxicity [18]. However, short term stability within the body and fast pNP clearance from bloodstream are pivotal barriers to surpass in order to achieve reliable therapeutic alternatives. These drawbacks imply periodical administration of the pNPs and the exposition of the patient to peaks of highly concentrated genotoxic drugs what increases stress associated to treatment. In this regard, immobilized drug delivery platforms capable of a sustained release pose an interesting alternative to intravenous administered drugs since they maintain a constant and long lasting drug concentration in the bloodstream.

Bacterial Inclusion Bodies (IBs) are amyloid like protein particles that occur during recombinant biofabrication processes. These particles gather many features from pNPs, like their capability to be modified in the genetic source, following a bottom up approach, in order to obtain functionally diverse carriers $[19,20]$. Nevertheless, IBs are significantly bigger entities than pNPs, with diameters from $100 \mathrm{~nm}$ up to $1 \mu \mathrm{m}$, belonging to the insoluble fraction under physiological conditions, what makes them easier to isolate in a cost effective manner. IBs are structured in a sponge like conformation in which a network of amyloid fibrils holds quasi soluble protein species [21]. These structures have been shown to act as other functional amyloids like the secretory granules found in the endocrine system [22]. IBs contain functional protein that can be released along time under the appropriate conditions [23].These features have been previously described and exploited rendering promising results in terms of protein stability and biocompatibility in both, in vitro and in vivo approaches, when a given protein is administered packed as IBs $[24,25,26]$. Nevertheless, nanostructured protein release from IBs has never been described.

In this work, we report for the first time the use of IBs as reservoirs of targeted pNPs. We describe direct release of self-assembled pNPs from IBs in a fully functional way in vitro 
and in vivo. In this regard, it is important to highlight that released pNPs are able to effectively target cells and tissues by specific receptor recognition. Our system exploits the combined nanoscale properties provided by pNPs with the mesoscale features of the IBs. In addition, we show the potential of implantable IBs to provide a long lasting source of targeted pNPs actively directed to distant sites from the primary implantation point.

In detail, two modular self-assembling proteins targeting CXCR4 receptor, T22-GFP-H6 and R9-GFP-H6, were produced as IBs. These IBs released pNPs specifically directed to CXCR4 ${ }^{+}$cells in both, in vitro and in vivo models. Importantly, T22-GFP-H6 IBs provided significant amounts of targeted pNPs as long as 10 days after subcutaneous implantation in a xenograft colorectal cancer mouse model that traveled through the bloodstream to efficiently accumulate in target CXCR4+ tumor cells. 


\section{Materials and Methods:}

Protein overexpression and Inclusion body isolation.

T22-GFP-H6, R9-GFP-H6 and VP1-GFP (Gene bank accession number: KM242650.1) modular proteins were coded by the expression vectors pET22b (Novagen), pET21a (Novagen) and pTrc99a respectively. T22 and R9 are cationic peptide ligands to the CXCR4 receptor while VP1 is a foot and mouth disease virus capsid protein employed as aggregation domain to favor IB deposition. These domains were fused to a green fluorescent protein (GFP). In the cases of R9-GFP-H6 and T22-GFP-H6 a polyhistidine tag was also incorporated to the c-terminus of the modular protein as an architectonic tag to induce the self-assembling of the resulting modular proteins in combination with the cationic n-terminal peptide. The constructs encoding T22-GFP-H6, R9-GFP-H6 and VP1GFP were transformed into the Escherichia coli (E. coll) strains Origami B, Rosetta (DE3) and JGT4 [27] respectively.

IB production was carried out in $400 \mathrm{~mL}$ of Luria Broth (LB) in $2 \mathrm{~L}$ shake flasks by conventional protein over expression. Briefly, induction of protein production was performed by $1 \mathrm{mM}$ isopropyl $\beta$-D-1-thiogalactopyranoside (IPTG) addition (final concentration) in bacterial cell cultures at early exponential growth phase, $\mathrm{OD}_{550}$ at 0.5 . Bacterial cell cultures were further incubated for $3 \mathrm{~h}$ at $37^{\circ} \mathrm{C}$ and $250 \mathrm{rpm}$. Samples were then harvested by centrifugation, $10.000 \mathrm{~g}$ for $15 \mathrm{~min}$ at $4{ }^{\circ} \mathrm{C}$ and a combination of mechanical and enzymatic procedures was applied for cell disruption. First, cell pellets were resuspended in lysis buffer (50 mM Tris- $\mathrm{HCl}, 10 \mathrm{mM} \mathrm{NaCl}, 1 \mathrm{mM}$ EDTA) and protease inhibitors: phenylmethylsulfonyl (PMSF) $0.4 \mathrm{mM}$ and Complete EDTA-Free (Roche) added. Then, enzymatic digestion was carried out by lysozyme added at $1 \mu \mathrm{g} / \mathrm{mL}$ for $2 \mathrm{~h}$ at $37^{\circ} \mathrm{C}$ and $250 \mathrm{rpm}$. After cell wall digestion, five rounds of French Press at 1200 psi were carried out and lysates were frozen at $-80^{\circ} \mathrm{C}$. Samples were thawed and mild detergent washing was performed by Triton X-100 addition $(0.2 \% \mathrm{v} / \mathrm{v})$ for $1 \mathrm{~h}$ at room temperature (RT) under vigorous agitation. IBs were collected by centrifugation at 15.000 $\mathrm{g}$ for $15 \mathrm{~min}$ at $4{ }^{\circ} \mathrm{C}$ and resuspended again in lysis buffer to wash out previous purification reagents. DNAse treatment, $0.6 \mu \mathrm{g} / \mathrm{mL} 1 \mathrm{~h}$ at $37^{\circ} \mathrm{C}$, was performed and presence of remaining viable bacteria checked by plating $100 \mu \mathrm{L}$ of IBs sample onto LB plates and culturing them overnight $(\mathrm{ON})$ at $37^{\circ} \mathrm{C}$. Freeze/Thaw cycles were applied until no colony was observed on the plates. Finally, IBs were washed in deionized sterile water, centrifuged at $15.000 \mathrm{~g}$ for $15 \mathrm{~min}$ at $4{ }^{\circ} \mathrm{C}$, and pellets stored at $-80^{\circ} \mathrm{C}$ until further use. IB 
quantification was carried out by western blot against GFP protein using GFP-H6 soluble protein at known concentration to generate the standard curve from which IBs quantification was inferred. This quantification was performed by ImageJ software $(\mathrm{NIH})$. $13.35 \mu \mathrm{g}$ of T22-GFP-H6, $3.15 \mu \mathrm{g}$ of R9-GFP-H6 and $3.55 \mu \mathrm{g}$ of VP1-GFP IBs per $\mathrm{mL}$ of cell culture were obtained respectively.

IB visualization in the producing bacteria strain

After IB production, cells were centrifuged at $5000 \mathrm{~g}$ for $15 \mathrm{~min}$ and the pellet was resuspended and fixed using a $4 \%$ paraformaldehyde solution for $30 \mathrm{~min}$ at room temperature (RT). Samples were then observed under a Leica TCS-SP5 confocal laser scanning microscope (Leica Microsystems CMS GmbH) in a Plan-Apochromatic 63x (NA 1.4, oil) objective. GFP-based proteins were excited with an Argon laser (488 nm). Finally, an intensity colored palette was applied to the obtained images using ImageJ software in order to improve fluorescence distribution observation.

\section{Protein release in vitro}

Purified IBs were resuspended in phosphate buffered saline (PBS) at $1 \mathrm{mg} / \mathrm{mL}$, and incubated at $37^{\circ} \mathrm{C}$. Samples were taken at $0 \mathrm{~h}, 0.5 \mathrm{~h}, 1 \mathrm{~h}, 3 \mathrm{~h}$, and $24 \mathrm{~h}$ and centrifuged for $15 \mathrm{~min}$ at $15000 \mathrm{~g}$ and $4{ }^{\circ} \mathrm{C}$. Soluble and insoluble fractions were further processed for western blot and FESEM imaging. In all the cases pellets corresponding to the insoluble fraction (IBs) were resuspended in PBS at the same final volume than their soluble counterpart (pNPs) for comparison.

\section{Field Emission Scanning Electron Microscopy (FESEM)}

Microdrops of $3 \mu \mathrm{L}$ of triplicate samples were directly deposited onto silicon wafers (Ted Pella Inc.) for 2 min and sample excess removed by capillarity using filter Whatman paper (GE Healthcare). Samples were further air dried and immediately observed at nearly native state without coating with a high resolution in-lens secondary electron detector in a Zeiss Merlin FESEM operating at $2 \mathrm{kV}$. For the qualitative approach, representative images of either insoluble (IBs, 200,000x of magnification) and soluble fractions (pNPs, $350,000 x$ of magnification) coming from protein release in vitro assay were obtained. For the quantitative approach, representative images at $170,000 x$ magnification of pNPs isolated at the optimal release incubation points observed by western blot $(0.5 \mathrm{~h}$ and $3 \mathrm{~h}$, respectively) were obtained. The diameter of randomly distributed 1795 particles from R9- 
GFP-H6 supernatants and 3637 from T22-GFP-H6 supernatants was determined for the size distribution assessment using ImageJ software (NIH).

\section{Western blotting}

Regular western blotting procedures were employed to analyze soluble and insoluble fraction from IBs. Briefly, equal volumes of each fraction were diluted in laemmli $4 x$ loading buffer. Insoluble and soluble fractions were boiled for $25 \mathrm{~min}$ and $5 \mathrm{~min}$ respectively at 98 ${ }^{\circ} \mathrm{C}$ and then $20 \mu \mathrm{L}$ loaded into a $15 \%$ sodium dodecyl sulfate (SDS) polyacrylamide electrophoresis gel. Gel running was carried out at a constant voltage of $100 \mathrm{~V}$ and transferred to a nitrocellulose membrane. GFP domain from the three model proteins employed in the study was detected using a rabbit polyclonal anti-GFP antibody (Santa Cruz Biotechnology) followed by a goat anti-rabbit secondary antibody conjugated to a horseradish peroxidase (BioRad). Membrane was developed by the addition of chloronaphthol and hydrogen peroxide. Densitometric analysis of the protein bands allowed us to determine relative amounts of protein between soluble and insoluble fraction. All the blots were performed in triplicate from independent experiments.

\section{Cell culture and pNP uptake assays}

HeLa cells acquired at ATCC (CCL2) were routinely cultured in MEM alpha medium (Gibco) containing $10 \%$ of fetal bovine serum (Gibco) in a humidified incubator a $37{ }^{\circ} \mathrm{C}$ and $5 \% \mathrm{CO}_{2}$. Note that the material used in the uptake experiments correspond to pNPs released from IBs and come from the soluble fraction of IBs suspension isolated by high speed centrifugation $\left(15.000 \mathrm{~g}, 15 \mathrm{~min}, 4^{\circ} \mathrm{C}\right)$.

\section{Flow cytometry}

Particle uptake assays were performed in 24 well plates at $70 \%$ of cell confluence. $2.5 \mu \mathrm{L}$ samples from soluble fractions (pNPs), coming from $1 \mathrm{mg} / \mathrm{mL}$ IB suspension, were added per well and incubated for $1 \mathrm{~h}$ at cell culture conditions. Then, incubation plates were washed in DPBS (Gibco) and treated with trypsin at $1 \mathrm{mg} / \mathrm{mL}$ (Gibco) for $15 \mathrm{~min}$ at $37^{\circ} \mathrm{C}$. This "harsh" trypsin digestion allowed to completely remove protein externally adhered to cells [28].Competition assays were performed as described above following incubation with $1 \mu \mathrm{M}$ of $\mathrm{AMD} 3100$ (Sigma) for $1 \mathrm{~h}$ at $37{ }^{\circ} \mathrm{C}$ and $5 \% \mathrm{CO}_{2}$. Note that AMD3100 (octahydrochloride hydrate) has been described as a potent CXCR4 receptor antagonist. Cells were then processed in a FACS-Canto flow cytometer (Becton Dickinson) using a 15 
$\mathrm{mW}$ air-cooled argon ion laser at $488 \mathrm{~nm}$ for GFP fluorescence excitation and a D detector (530/30 $\mathrm{nm}$ bandpass filter) for detection of their fluorescence emission.

\section{Confocal Microscopy}

Nanoparticle uptake was also assessed by confocal microscopy. HeLa cells were cultured in MatTek culture dishes (MatTek Corp.) until reaching subconfluency. The soluble fractions, containing pNP released from $1 \mathrm{mg} / \mathrm{mL}$ IBs suspension, were added and further incubated during $1 \mathrm{~h}$. Cell membranes were stained with CellMaskTM DeepRed (Molecular Probes) and nuclei with Hoescht 33342 (Molecular Probes) for 10 min before being washed in PBS. Cells were then recorded with a Leica TCS-SP5 confocal laser scanning microscope (Leica Microsystems CMS GmbH) using an Apo63x/1.4 (oil HC x PL APO lambda blue) objective. GFP-based pNPs were excited by an Argon laser (488 nm), Cell mask by a HeNe laser $(633 \mathrm{~nm})$ and Hoescht by a blue diode $(405 \mathrm{~nm})$.

\section{In vivo biodistribution of bacterial IBS}

Five-week-old female Swiss nu/nu mice weighing between 18 and $20 \mathrm{~g}$ (Charles River) and maintained in SPF conditions, were used for in vivo studies. All the in vivo procedures were approved by the Hospital de Sant Pau Animal Ethics Committee and performed according to European Council directives. To generate the subcutaneous (SC) mouse model, $10 \mathrm{mg}$ of SP5 CCR tumor tissue were obtained from donor animals, and subcutaneously implanted in the anterior flanks of experimental Swiss nu/nu mice. When tumors reached $500 \mathrm{~mm}^{3}$ approximately, mice were randomly allocated and subcutaneously administered in the mouse posterior flank, far away from the tumor, with T22-GFP-H6 or VP1-GFP bacterial IBs at $1 \mathrm{mg} / \mathrm{mouse}$ dose resuspended in a $150 \mu \mathrm{L}$ saline solution. Control mice were administered with the same volume of saline solution.

After IBs administration, whole- body mice were monitored at short ( $5 \mathrm{~h}$ ) and long-times (1 $\mathrm{d}, 2 \mathrm{~d}, 5 \mathrm{~d}$ and $10 \mathrm{~d}$ ) to determine the retained GFP fluorescence in the subcutaneous IB implants located in the posterior mouse flank using the IVIS® Spectrum equipment (PerkinEImer Inc.). Following, $1 \mathrm{~mL}$ of blood was collected by intracardiac puncture and plasma was obtained by centrifuging at $600 \mathrm{~g}, 10 \mathrm{~min}, 4^{\circ} \mathrm{C}$. Fluorescence emitted by the obtained plasma was, then, recorded ex-vivo using the IVIS equipment at the selected times $(5 \mathrm{~h}, 1 \mathrm{~d}, 2 \mathrm{~d}, 5 \mathrm{~d}$ and $10 \mathrm{~d})$ post-administration of bacterial IBs. Mice were subsequently euthanized and tumor, brain, lung and heart, kidney, liver and bone marrow 
were collected and examined separately for ex-vivo GFP fluorescence in an IVIS $B$ Spectrum equipment.

The fluorescent signal (FLI) was first digitalized, displayed as a pseudocolor overlay, and expressed as radiant efficiency. The FLI ratio was calculated dividing the FLI signal from the protein-treated mice by the FLI auto-fluorescent signal of control mice. In order to estimate the percent of the subcutaneously injected IBs dose that reached the tumor or normal organs, we calculated the Area Under the Curve (AUC (mg $x$ day)). This was done after plotting the amount of protein (mg) versus time (days) for each localization, and applying the trapezoidal method, considering the following equivalencies at time $0 \mathrm{~min}$ after SC administration. $5.57 \times 10^{9}$ and $1.24 \times 10^{10}$ fluorescent units were equivalent to 1 $\mathrm{mg}$ of T22-GFP-H6 IBs protein or $1 \mathrm{mg}$ of VP1-GFP IBs protein, respectively

\section{Multiple immunofluorescence assay.}

The presence and localization of IBs and released pNPs around the injection point in the mouse posterior flank (as subcutaneous depositions), into blood vessels of the hypodermis and in tumor tissue of the anterior mouse flank were assessed by multiple immunofluorescence labeling of formalin-fixed paraffin-embedded (FFPE) samples using standard protocols. Samples were taken after $5 \mathrm{~d}$ upon IBs administration. Primary antibodies anti-GFP (1:250, Abcam) and anti-PECAM-1 (1:200; Santa Cruz Biotechnology, Inc.) were incubated $\mathrm{ON}$ at $4 \stackrel{\circ}{\circ}$. Then, the secondary antibodies: donkey anti-goat IgGCy3 (Jackson) for PECAM-1 and chicken IgG-Cy2 for GFP. Slides were then stained with DAPI (1:10000 in TBS) for $10 \mathrm{~min}$ RT, rinsed with water, mounted and analyzed under fluorescence microscope (405 nm, 488 Cy2 and 532/561 filters). Representative pictures were taken using confocal Leica TCS SPE at 400x magnification.

\section{Statistical analysis}

T- tests assuming unequal variances were performed to assess differences in in vitro assays with a minimum $n=3$. Past 3 open access software was employed to carry out statistical analysis. The Mann-Whitney U-tests were used to compare tumor tissue fluorescence emission (FLI) between groups in in vivo experiment, using the SPSS vs11.0 package (IBM). All quantitative values were expressed as mean \pm standard error of the mean (SEM).. Differences between groups were considered significant at $p<0.05$. 


\section{Results:}

Bacterial IBs formed by the recombinant modular proteins VP1-GFP, R9-GFP-H6 and T22-GFP-H6, detailed in Figure 1, panel a, were successfully produced in E. coli cell factories. Protein overexpression rendered insoluble protein deposits in the range from $100 \mathrm{~nm}$ to $800 \mathrm{~nm}$ in diameter. IB size characterization of the material used in the present work was performed in a previous study [20]. As it can be observed in Figure 1b, left panel, focused fluorescent signal showed IB deposition at the bacteria poles but we also detected fluorescence all over the cytoplasm indicating presence of their soluble counterpart. In addition, the co-existence of soluble and insoluble protein species within the bacteria exhibited distinct patterns depending on the IB fabrication setup, namely producing strain and IB forming protein. In this regard T22-GFP-H6 and R9-GFP-H6 producing bacteria showed a higher extent of soluble protein than VP1-GFP samples.

FESEM micrographs of purified IBs revealed pseudo-spherical particles with different grades of surface complexity. VP1-GFP IBs displayed mostly smooth surface while R9GFP-H6 and T22-GFP-H6 IBs showed increased surface roughness exhibiting a particulate coating. Interestingly, significantly smaller particles were also observed nearby R9-GFP-H6 and T22-GFP-H6 IBs suggesting a direct release of pNPs from IBs (Figure 1b, right panel). In order to study in detail this event we further analyzed by FESEM the soluble fractions obtained after the centrifugation of purified IBs suspensions where we efficiently separate IBs form released soluble protein material. In these soluble samples, we observed rounded nanostructures confirming pNPs release from the main aggregate (IBs) (Figure 1c). Of note R9-GFP-H6 and T22-GFP-H6 have been previously described as proteins with self-assembling capacity able to effectively generate soluble pNP driven by the presence of positively charged peptides at the amino terminus such as T22 and R9 in combination with a polyhistidine tag at the carboxy terminus (Figure 1, panel a) [17]. Qualitative evaluation of pNPs depicted in FESEM images revealed a rather polydisperse size distribution exposing particles with diameters sizing from $20 \mathrm{~nm}$ to $80 \mathrm{~nm}$ in both T22GFP-H6 and R9-GFP-H6 samples. Additionally, magnification of pNPs showed a brighter outer ring and darker inner region within nanoparticle architecture. This observation suggested a toroidal conformation of the pNPs in accordance with previous studies [29]. As expected, VP1-GFP samples did not show any nanostructured entity in its soluble fraction since the fusion protein lacks the oligomerization domains. 
a)
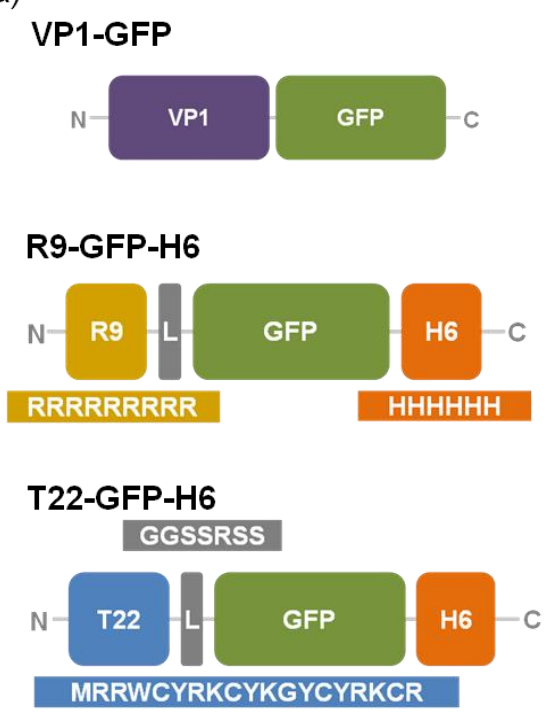
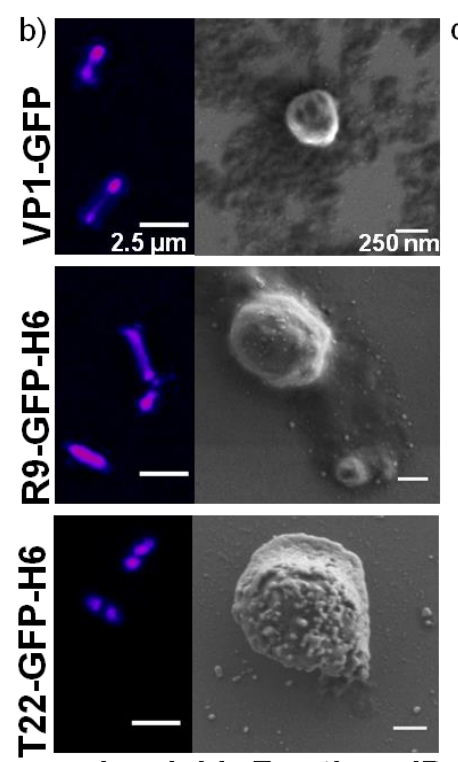

Insoluble Fraction : IBs
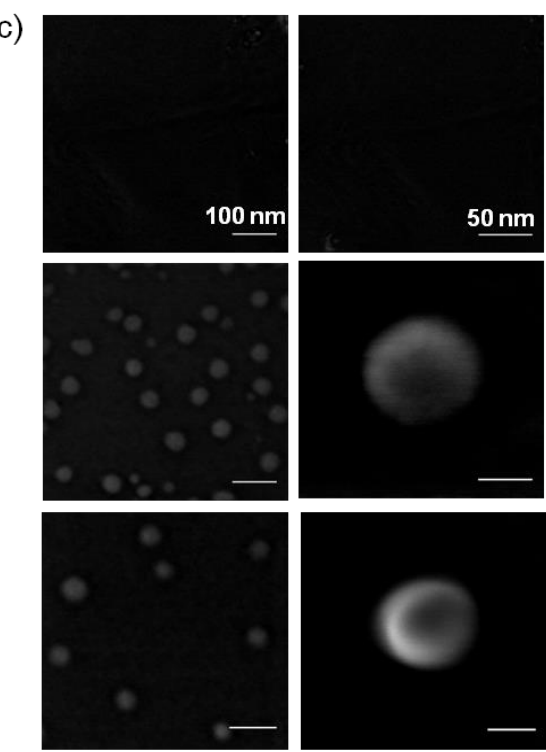

Soluble Fraction : pNPs

Figure 1. Architectonic features of T22-GFP-H6, R9-GFP-H6 and VP1GFP a) Schematic representation of the aggregation model protein VP1-GFP and the self-assembling modular proteins R9-GFP-H6 and T22-GFP-H6. Sizes of the boxes are only indicative b) Left panel, confocal images of bacteria producing IBs. Right panel, FESEM micrographs of isolated IBs. c) FESEM detail of pNPs (present in the soluble fraction) isolated from purified IBs (insoluble fraction). pNPs were obtained by isolating by centrifugation the soluble fraction of an IB suspension at $1 \mathrm{mg} / \mathrm{mL}$.

Next we studied protein release from IBs (insoluble fraction) to the soluble fraction at different time points (Figure 2a). For this, IBs were resuspended in PBS at $1 \mathrm{mg} / \mathrm{mL}$ and incubated at $37^{\circ} \mathrm{C}$. Soluble and insoluble fractions were then isolated from these samples at different times and presence of protein immune detected by western blot. Protein amount released from IBs to the soluble fraction was higher for T22-GFP-H6 samples than for R9-GFP-H6 at longer incubation times. VP1-GFP did not show detectable amounts of protein in the soluble fraction at any tested time. Interestingly, T22-GFP-H6 exhibited increasing amounts of protein in the soluble fraction reaching its maximum at $3 \mathrm{~h}$ in which the soluble protein corresponded to the $14.6 \%$ of the total protein, but rendering clearly detectable bands till $24 \mathrm{~h}$ after IBs resuspension (10\% of soluble protein). This profile was indicative of a progressive protein release from IBs. In the case of R9-GFP-H6 samples, the amount of protein obtained in the soluble fraction could be detected till $3 \mathrm{~h}$ after incubation with a maximum intensity at $30 \mathrm{~min}, 16 \%$ of soluble protein. Interestingly, at longer incubations time points the amount of released protein exhibited a marked drop. 
R9-GFP-H6 IBs may contain an external layer of loosed pNPs easily resolubilized but with a poor stability in the assay conditions (Figure $\mathbf{2 a}$ and ai). In order to analyze in vitro if the released protein from IBs occurred in form of single polypeptides or arranged as selfassembled pNPs, a morphometric analysis of ultrastructure was performed for the soluble fraction of IBs suspensions at distinct incubation times with FESEM (Figure 2b). Abundant pNPs were observed in accordance with previous results at distinct timepoints, $0 \mathrm{~h}, 1 \mathrm{~h}$ and $24 \mathrm{~h}$ for R9-GFP-H6 and T22-GFP-H6 samples. As expected, no pNPs were visualized in VP1-GFP samples. Self-assembled pNPs were detected immediately after IB resuspension in PBS, time $0 \mathrm{~h}$, and at all the tested times. Thus, we confirmed that a significant part of the signal obtained in the western blot analysis was given by a nanostructured fraction of the protein. In addition, size distribution was determined for both R9-GFP-H6 and T22-GFP-H6 released pNPs. As it can be observed in Figure 2 bi, T22GFP-H6 exhibited particles with a peak between 10 and $20 \mathrm{~nm}$ in diameter, slightly smaller than the ones obtained for R9-GFP-H6. In this last case the peak was shifted between the 20 and $30 \mathrm{~nm}$. In both samples, bigger particles (untill $130 \mathrm{~nm}$ ), could be observed but they represented a negligible number of the released material. Interestingly, these results are in accordance with size distribution obtained for T22-GFP-H6 pNPs when produced from the protein soluble form [30].
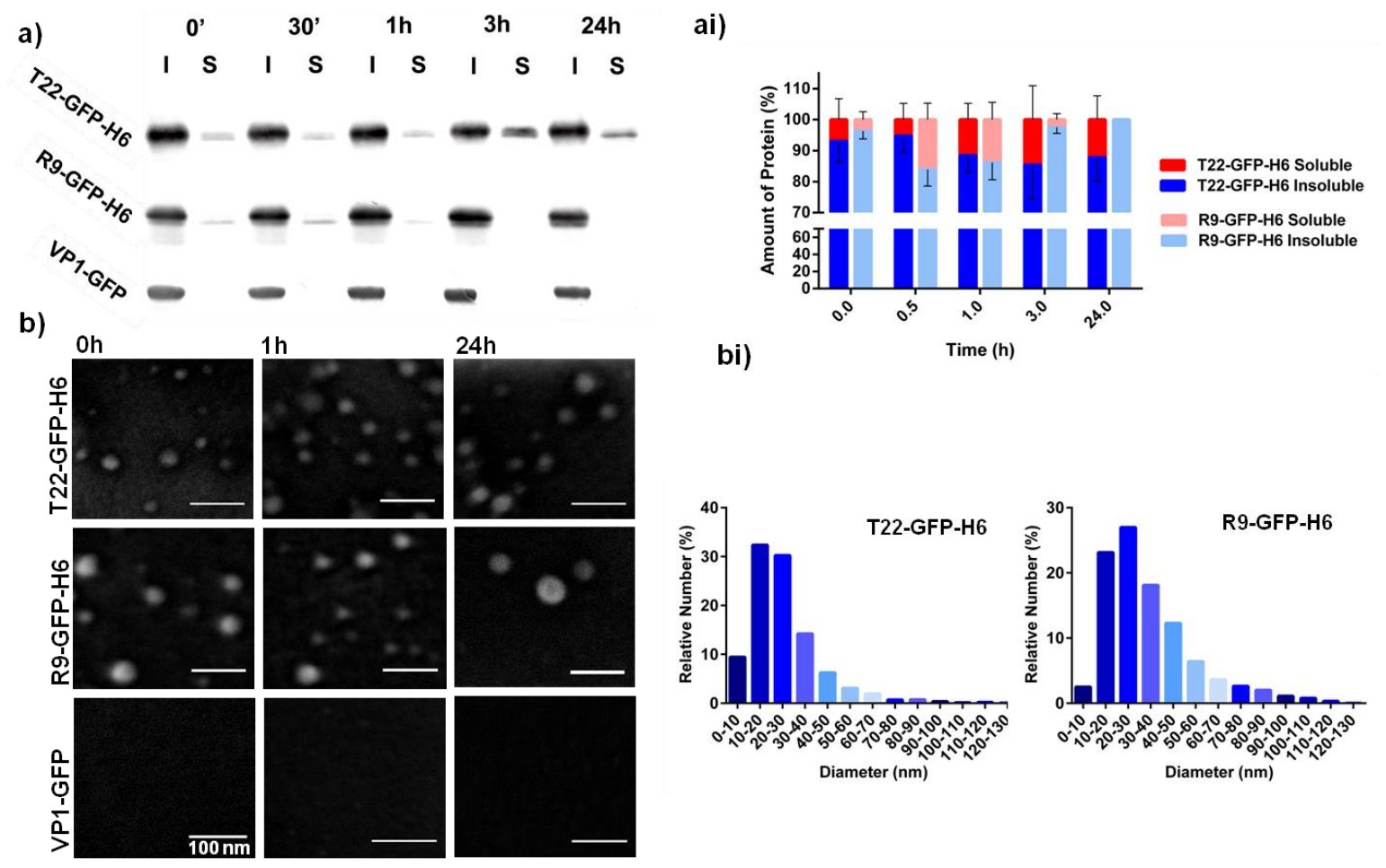
Figure 2. In vitro protein release from T22-GFP-H6, R9-GFP-H6 and VP1-GFP IBs a) Protein amount determination by western blot of insoluble fraction (I) and soluble fraction (S) at different incubation time points ai) Relative protein quantification from the soluble and insoluble fraction of T22-GFP-H6 and R9-GFP-H6 samples at distinct incubation time points. b) FESEM morphometric analysis of pNP present in the soluble fraction and released from IBs at $0 \mathrm{~h}, 1 \mathrm{~h}$ and $24 \mathrm{~h}$ of IB suspension incubation. bi) Size distribution of pNPs for T22-GFP-H6 and R9-GFP-H6.

To validate if R9-GFP-H6 and T22-GFP-H6 pNPs released from IBs maintained their bioactive properties, such as CXCR4 receptor avidity, in vitro internalization studies of released protein particles were carried out (Figure 3). pNPs from R9-GFP-H6 and T22GFP-H6 showed significant internalization after $1 \mathrm{~h}$ of incubation in CXCR4 ${ }^{+}$HeLa cells. In addition, when the CXCR4 inhibitor AMD 3100 was added, pNP uptake was completely blocked indicating that R9-GFP-H6 and T22-GFP-H6 get into the cells by CXCR4 receptor-specific mediated endocytosis. As expected, no uptake was observed for VP1GFP samples. This data was confirmed by confocal microscopy (Figure 3c).

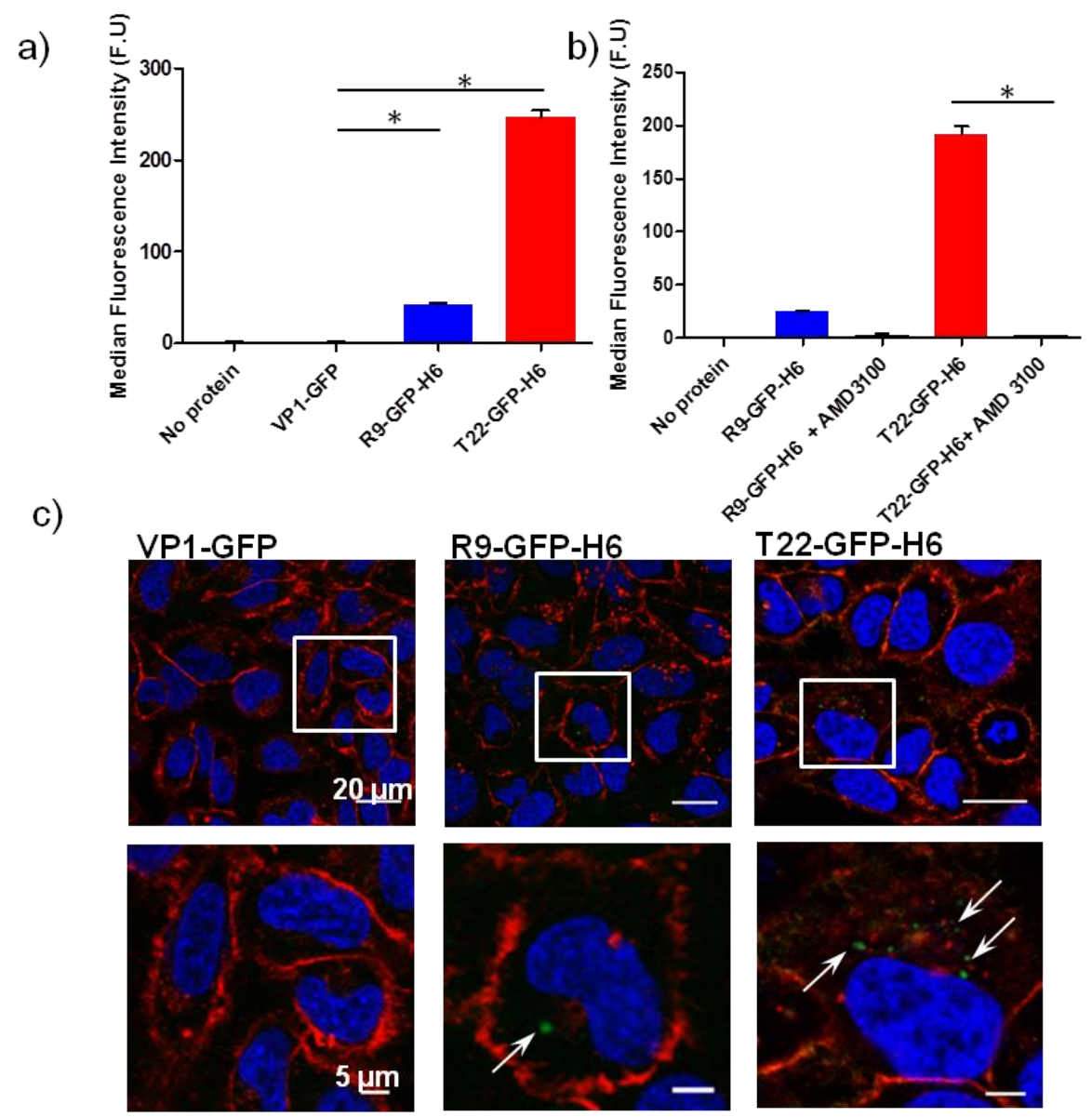


Figure 3. Internalization of pNPs released and isolated from IB suspensions in CXCR4+ ${ }^{+}$cells. a) Internalization of soluble pNPs (isolated from IBs) monitored by flow cytometry $1 \mathrm{~h}$ after exposure to HeLa cells .b) Inhibition of T22-GFP-H6 and R9-GFP-H6 pNPs (isolated from IBs) internalization by CXCR4 receptor specific antagonist AMD3100. c) Confocal images of HeLa cells exposed to isolated pNPs (released from IBs) for $1 \mathrm{~h}$. In blue: cell nuclei, in red: cell membrane, in green: internalized pNPs. *: $p<0.05$

Finally, as a proof of concept for the developed biomaterial acting as reservoirs of pNPs, in vivo assays were also performed. Colorectal cancer xenograft models bearing subcutaneous tumors in the mouse anterior flank were subcutaneously injected in the mouse posterior flank with $1 \mathrm{mg}$ of T22-GFP-H6 IBs per mouse, far away from the tumor location. SC Injection of $1 \mathrm{mg}$ of VP1-GFP IBs were used as non-pNP releasing negative control. Screening of fluorescence by IVIS revealed a relatively low release of the material from the injection point for VP1-GFP IBs. The release of T22-GFP-H6 was significantly higher, with a marked drop in fluorescence during the first 2 days that was then stabilized maintaining the levels until day 10 after injection (Figure $4 \mathbf{4 a}$ ).

Looking at the fluorescence emitted by the protein in blood it can be drawn that detectable amounts of T22-GFP-H6 and VP1-GFP were released from the injection site, reached the blood vessels in the hypodermis and entered the blood stream (Figure $\mathbf{4 b}$ ). The amount of T22-GFP-H6 material able to reach the blood stream was significantly higher than that the VP1-GFP protein, probably due to their capability to release a higher extent of protein and to self-assemble in pNPs. The concentration of T22-GFP-H6 in blood showed a progressive increase until day 5 and was detectable until 10 days after IB subcutaneous injection. The concentration of VP1-GFP (pNP negative control) in blood did not experiment important changes along time. These results are in accordance with the multiple immunolabeling at the injection site. As it can be observed in Figure 4c, T22GFP-H6 showed important level of disaggregation of the subcutaneously injected IBs leading to a high degree of dispersion of the forming material and penetration into the surrounding tissue. Noteworthy, GFP labeling was also detected inside blood vessels, delimited by the immunolabeling of the endothelial marker PECAM. This observation provided direct evidence of the high capability for the released T22-GFP-H6 protein to enter the vessels and subsequently the bloodstream enabling its further distribution to specific tissue in a distal point of the body. On the contrary, VP1-GFP showed a compact distribution of the deposited IBs within the subcutaneous tissue with little spreading, making it more difficult to reach and enter the blood vessels. 
a)
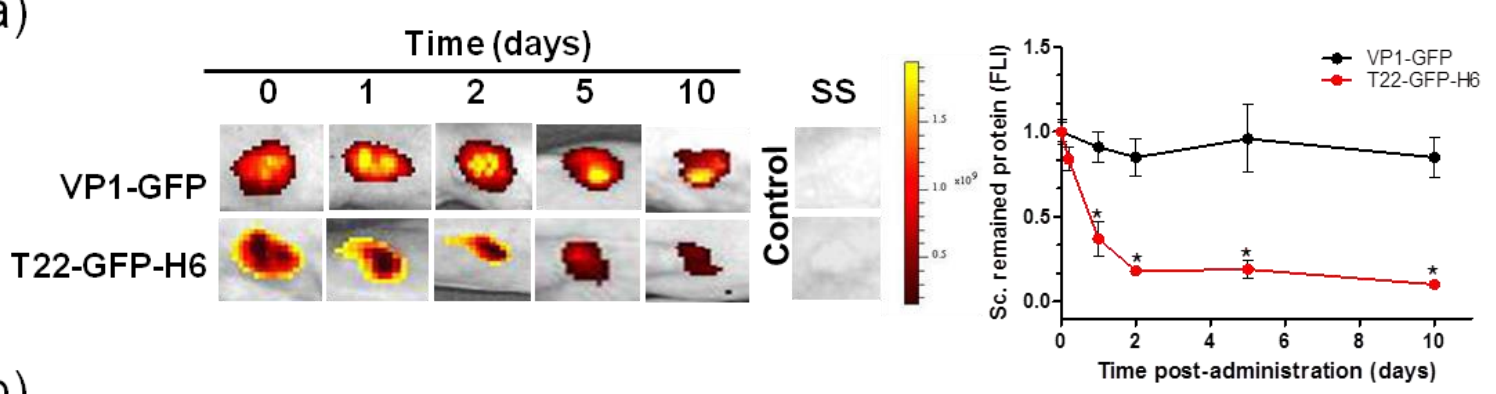

b)

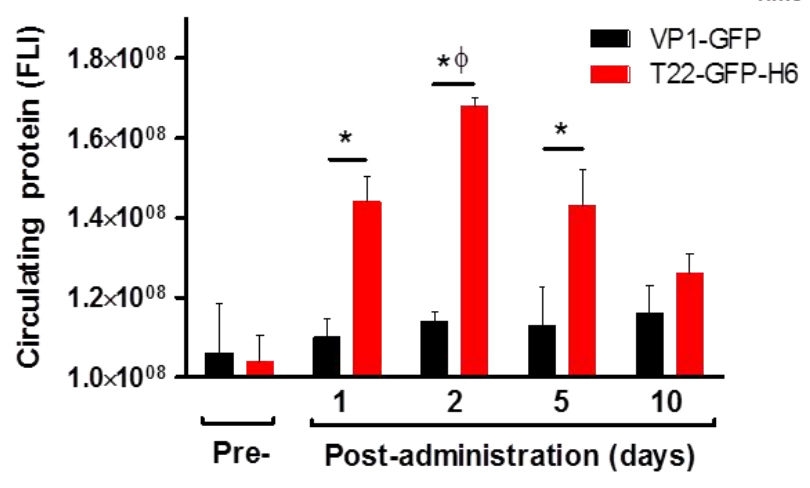

c)
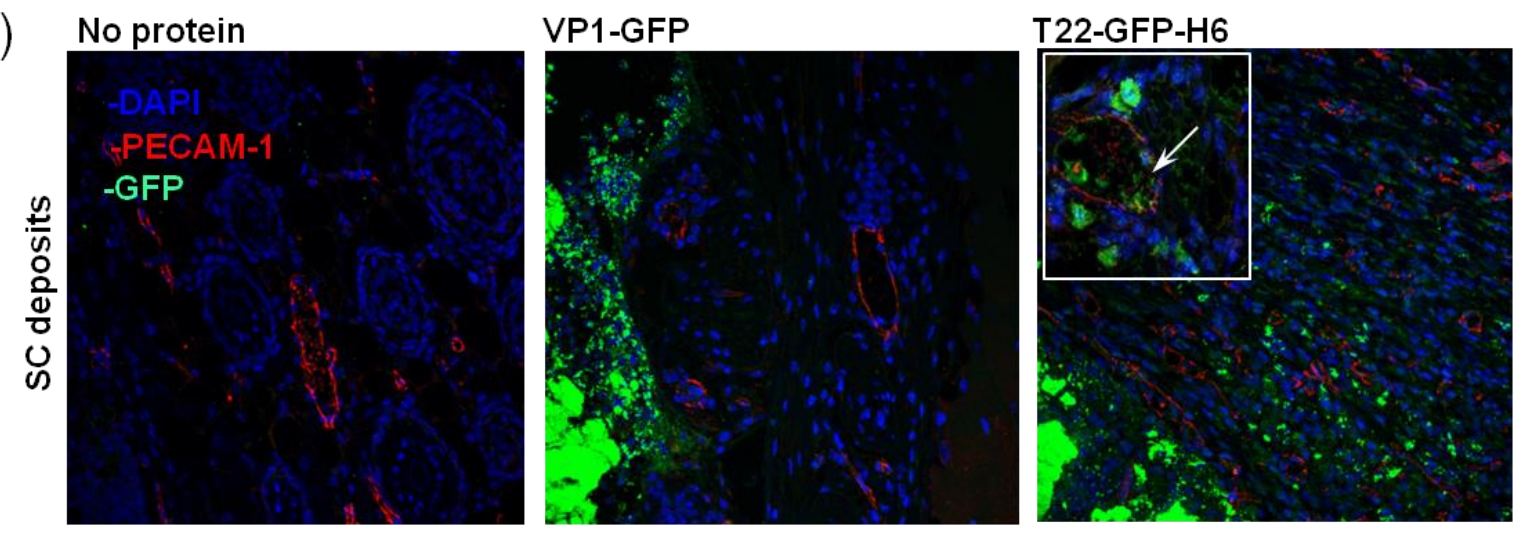

Figure 4. Assessment of T22-GFP-H6 and its respective control VP1-GFP protein release in mice upon subcutaneous administration of $1 \mathbf{~ m g ~ d o s e / m o u s e ~ o f ~ e a c h ~ I B ~ t y p e . ~ a ) ~ O n ~ t h e ~ l e f t ~}$ panel, ex- vivo FLI representative images at the injection site after $0 \mathrm{~d}, 1 \mathrm{~d}, 2 \mathrm{~d}, 5 \mathrm{~d}$ and $10 \mathrm{~d}$. On the right graphic representation of the FLI obtained at the injection site for all the animals. b) Protein detected in blood at $0 \mathrm{~d}, 1 \mathrm{~d}, 2 \mathrm{~d}, 5 \mathrm{~d}$ and $10 \mathrm{~d}$ upon IB subcutaneous injection. c) Multiple immunofluorescence image at the injection site after $5 \mathrm{~d}$ post IBs administration displaying in green GFP protein, in blue cell nuclei and in red the endothelial marker PECAM-1.*: p-value $<0.05$ between groups; ${ }^{\phi} p$-value $<0.05$ between the rest of T22-GFP-H6 treated groups.

In order to track the protein released from these IBs, the emitted fluorescence was measured to assess their uptake in tumor tissue, as well as in brain, lung, heart, liver, kidney and bone marrow to assess unspecific accumulation in non-target organs. Protein was detected in tumors as it can be observed in Figure 5. Noteworthy, fluorescent signal 
increased along time showing stable accumulation of pNPs in the tumor for T22-GFP-H6 sample. T22-GFP-H6 exhibited maximum accumulation at day 5 and slightly decreased till day 10 upon IB injection. VP1-GFP injected animals also exhibited fluorescence at all tested timepoints in tumors, denoting protein release from the material deposited at the injection site, but no accumulation during this period was observed. In fact, the retained amount of protein in the tumor and the subsequent fluorescence levels decreased along time and were markedly lower than the ones obtained for T22-GFP-H6 samples at long times, 5 and 10 days upon IB administration. Moreover, in the case of T22 empowered pNPs multiple immunofluorescence images displayed GFP signal clustered in the perinuclear region of tumor cells indicating the capability of released pNPs to be actively internalized by $\mathrm{CXCR} 4^{+}$malignant cells.

a)

T22-GFP-H6

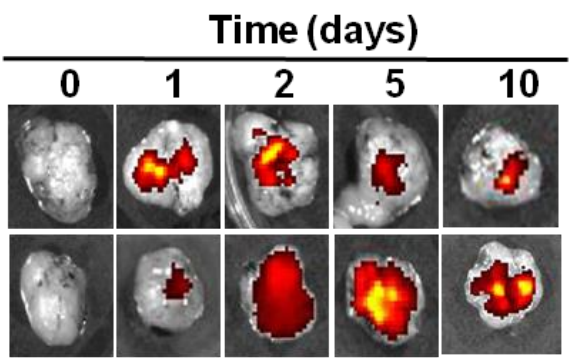

b)

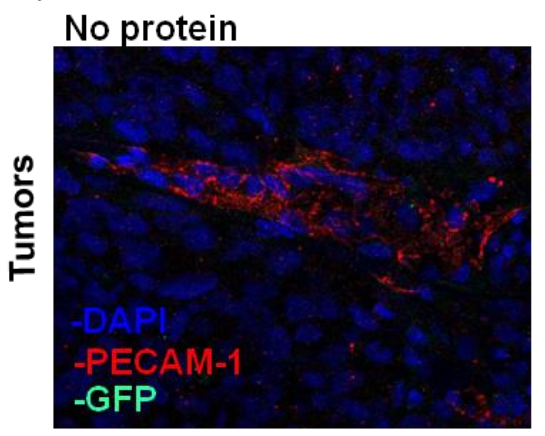

VP1-GFP

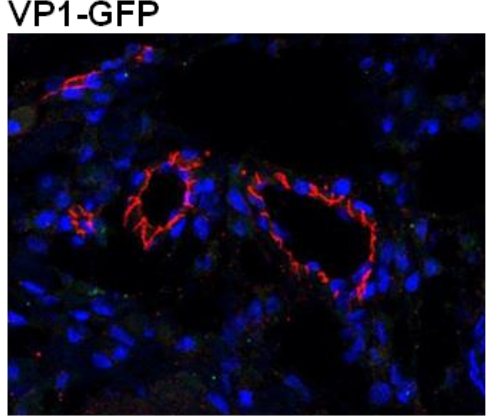

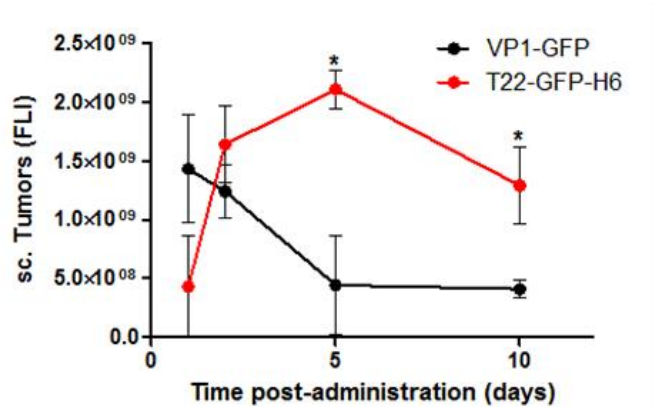

T22-GFP-H6

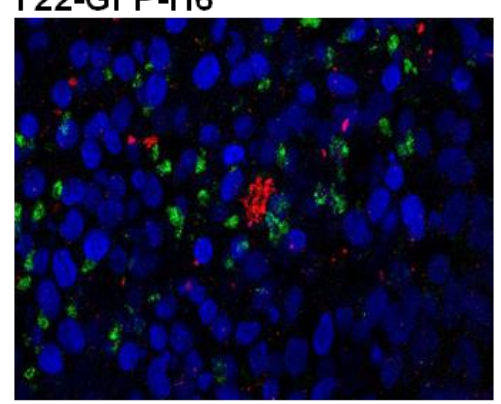

c)
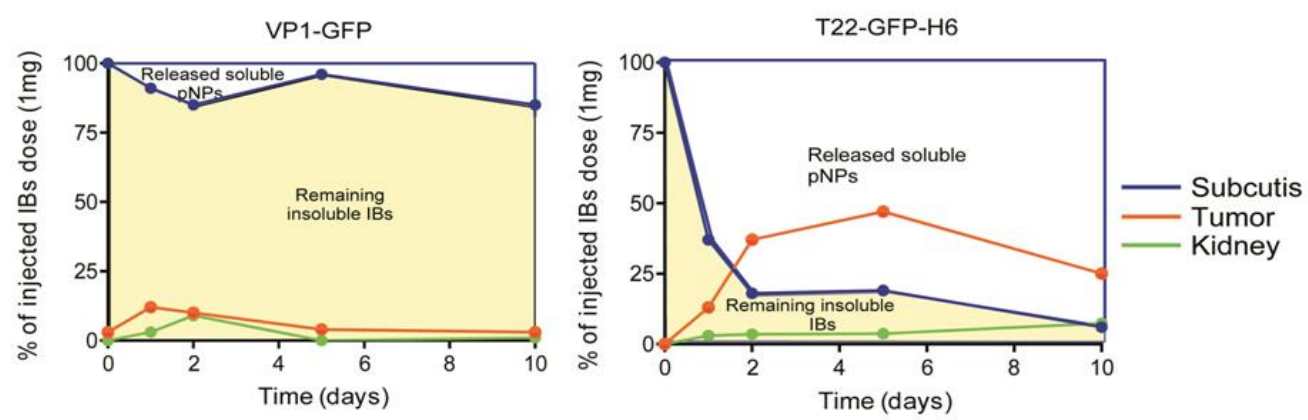
Figure 5. Tumor ex-vivo accumulation of T22-GFP-H6 and its respective control VP1-GFP proteins in mice upon subcutaneous administration of $1 \mathrm{mg}$ dose/mouse of each IB type. a) On the left panel, ex- vivo FLI representative images of protein accumulation in tumor after $1 \mathrm{~d}, 2 \mathrm{~d}$, $5 \mathrm{~d}$ and $10 \mathrm{~d}$ IB injection. On the right graphic representation of the FLI obtained for all the animals. b) Multiple immunofluorescence after $5 \mathrm{~d}$ post IBs administration image in tumor displaying in green GFP protein, in blue cell nuclei and in red the endothelial marker PECAM-1. * $p$-value $<0.05$ between groups. c) Plots describing the insoluble IBs remaining in the hypodermis, the amount of released soluble pNPs and the amount of soluble pNPs that reach the tumor and the kidney along time. The areas under the curve (AUCs) are used to estimate the percent of injected IBs and of released proteins that reach the tumor and renal tissues. Please, see Suppl. Table 1 for quantitative data.

Ex-vivo analysis of non-targeted organs revealed fluorescent signal at short times in kidney for T22-GFP-H6. This signal faded after 1 day indicating that part of the material is either cleared through these organs, in the case of protein in its monomeric form, or retained in the renal glomerule to be further recirculated to the bloodstream, in the case of nanostructured protein. On the contrary, VP1-GFP showed a much more erratic distribution in accordance with their non-targeted nature and incapability to generate pNPs. Several organs, particularly the liver, contained detectable amounts of the VP1-GFP protein 1 day post-injection.

Next, we estimated the percent of injected dose that reached the tumor or the kidney (the normal organ with highest accumulation) out of the total soluble protein released from the IBs in the hypodermis, after the subcutaneous administration of $1 \mathrm{mg}$ IBs dose. (Figure 5c, Suppl.Table 1). After administration of T22-GFP-H6 IBs, the protein was continuously released as soluble pNPs (83.6\%). Only a small percent of it remained in the hypodermis by day 10. Moreover, the released soluble protein accumulated mainly in tumor tissue $(33.7 \%)$, whereas a minor fraction $(2.7 \%)$ was uptaken by the kidney and negligible accumulation was detected in other normal organs. That implied 12.3 times more accumulation of T22-GFP-H6 pNPs in tumor than in kidney. The rest of the released soluble protein was likely degraded in blood or in tumor tissue after cell internalization. Noteworthy, excluding the pNP slow release, provided by the SC IBs administration, the distribution and degradation in the body of the released pNPs followed a similar pattern to the one we previously reported after direct intravenous administration of soluble T22-GFPH6 pNPs [18]. 
In contrast to T22-GFP-H6 IBs, a much lower amount of VP1-GFP IBs (14.2\%) was released as soluble protein. Out of that, 5.7\% of released protein was uptaken by the tumor whereas 3.3\% accumulated in the kidney (suppl. Table 1, Figure 5c). This data indicates that T22 peptide is effectively conferring selectivity to the T22-GFP-H6 pNPs released from IBs to CXCR4+ tumors while our non targeted control VP1-GFP showed, as expected, a poor selectivity in our model.

T22-GFP-H6

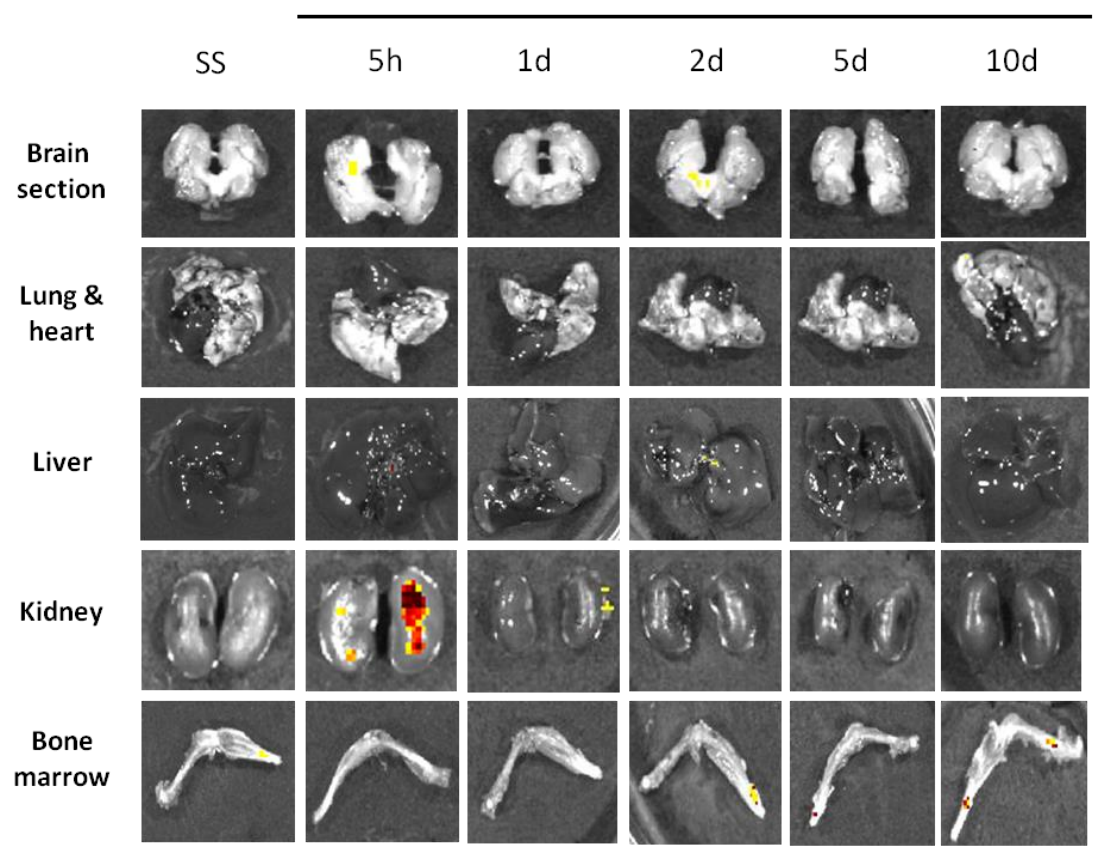

VP1-GFP-H6

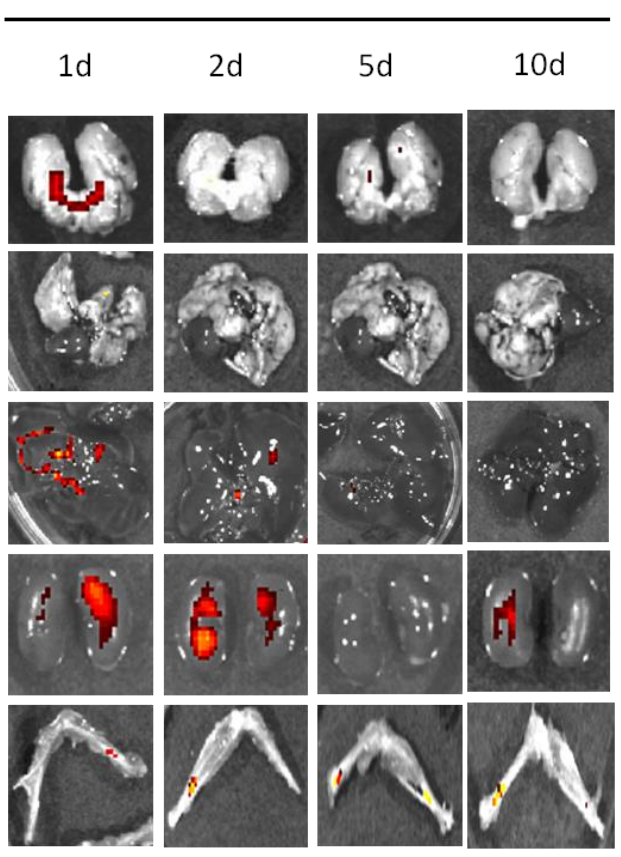

Figure 6. Organ biodistribution of T22-GFP-H6 and its respective control VP1-GFP in mice at $5 \mathrm{~h}$ and $1 \mathrm{~d}, 2 \mathrm{~d}, 5 \mathrm{~d}$ and $10 \mathrm{~d}$ upon subcutaneous administration of $1 \mathrm{mg}$ dose/mouse of each IB type. Representative ex vivo images of targeted and untargeted IB uptake in mouse brain, lung, heart, liver, kidney and bone marrow tissue after subcutaneous injection measured by GFPemitted fluorescence. 


\section{Discussion:}

Classical perception of bacterial IBs as non-functional protein aggregates has been overcome for a while. Many studies have shown the potential of these protein particles in several fields, reviewed elsewhere [31,32]. In biomedical research the protein nature of the material confers enormous structural and functional possibilities empowering the appearance of more complex and finest biomaterials. Other examples of the potential of protein based biomaterials are polymeric materials using as building blocks silk, elastin, collagen and resilin recombinant proteins or protein fragments. This kind of biomaterials has been shown able to render nanoparticles but also bigger, insoluble structures such hydrogels [33]. Nevertheless, the combination of both supramolecular conformations using the same recombinant construct has never been attempted. In our case, production of T22-GFP-H6 and R9-GFP-H6 modular proteins engineered to oligomerize into pNPs $[17,34]$, in a first level of structural complexity at the nanoscale, can be combined with their production and isolation in bigger entities as insoluble IBs, what confers a second grade of structural complexity. These multifaceted protein delivery platforms exhibit appealing features such as biocompatibility, biodegradability, cell targeting capacity, long lasting effect and plasticity to modulate their physicochemical properties. Hence, we expect when formed by proteins with a therapeutic activity they will be able of increasing treatment efficiency and reducing non-desired side effects. This idea is reinforced by the recent results obtained when producing self assembled pNPs formed by toxins or pro-apoptotic peptides replacing the GFP backbone and using the same architectonic tags than in the present work. In this scenario, toxin and pro-apoptotic based pNPs revealed a strong therapeutic potential after intravenous injection in colorectal cancer mouse model $[35,36]$. Our data prove the feasibility of producing pNPs, formed by self-assembling of modular proteins immobilized as IBs. The resulting pNPs were successfully isolated from those insoluble supramolecular structures, avoiding complex purification and refolding processes and therefore reducing substantially downstream costs [31]. Interestingly, although pNPs self-assembly has been described in non-physiological conditions [34] no evidence of pNP formation in the bacterial cytoplasm has been provided so far. Nevertheless, the presence of pNPs in straightforward isolated IBs, together with the observation of distinct surface roughness, resembling a particulate coating and even rounded structures in the nano scale attached to the IB surface (see suppl. Figure 1) allows to speculate that pNPs selfassembly could occur, at least partially, in the bacterial cytoplasm during protein over 
expression. In this situation part of the recombinant protein would skip the cell protein quality control machinery to be deposited in the insoluble amyloid-like aggregates. The coexistence of soluble and insoluble protein species inside the bacteria cytoplasm would enable the possibility for soluble pNPs to be trapped in the insoluble amyloid network as previously described for non-nanostructured soluble protein $[37,38]$.

As it happens with the conformational quality of the protein embedded in the IBs $[39,23]$ pNPs release from these protein deposits could also be tuned by the genetic modification of the forming protein. Distinct release patterns observed for proteins with the same GFP scaffold but different ligands, T22 and R9, exemplify how this material can be engineered from their genetic sequence to modulate their associated mechanical properties such as pNPs release profile. In our system, T22-GFP-H6 exhibited a sustained release along the tested times while R9-GFP-H6 showed a burst of pNPs after short incubation times.

Besides, IBs per se are a highly malleable biomaterial which physico-chemical properties can be modulated by adjusting other process variables such as harvesting time or protein overexpression temperature [40]. The proper choice of the bacterial genetic background used as cell factory has shown significant impact in biological activity of the resulting protein deposit and its morphometric parameters [41]. Interestingly, the genetic profile of microbial cell factories also influences pNPs features [29]. It is important to note that protein conformational quality of the resulting pNPs was not compromised by their production as IBs. Internalization assays in CXCR4 ${ }^{+}$cells and further uptake competition of isolated pNPs (released from IBs) with AMD3100 indicated that receptor specificity, directly dependent on the proper T22 ligand folding [29], remained intact. Targeting is crucial in DDS design since it allows reducing drug effective concentration, focuses the therapeutic action at the desired organ or cell type and restrain undesired off target effects. In this regard, our model system proved to be a simple "all in one" approach from the biofabrication point of view rendering complex sub-micron particles that act as a novel platform for the sustained release of fully active targeted pNPs.

Moving to the in vivo scenario, our injected IBs were able to release protein. This protein entered the blood stream, travelled through the mouse body and targeted distal CXCR4 ${ }^{+}$ tumors where significantly accumulated, being detectable after 10 days upon subcutaneous injection (Figure 7). 


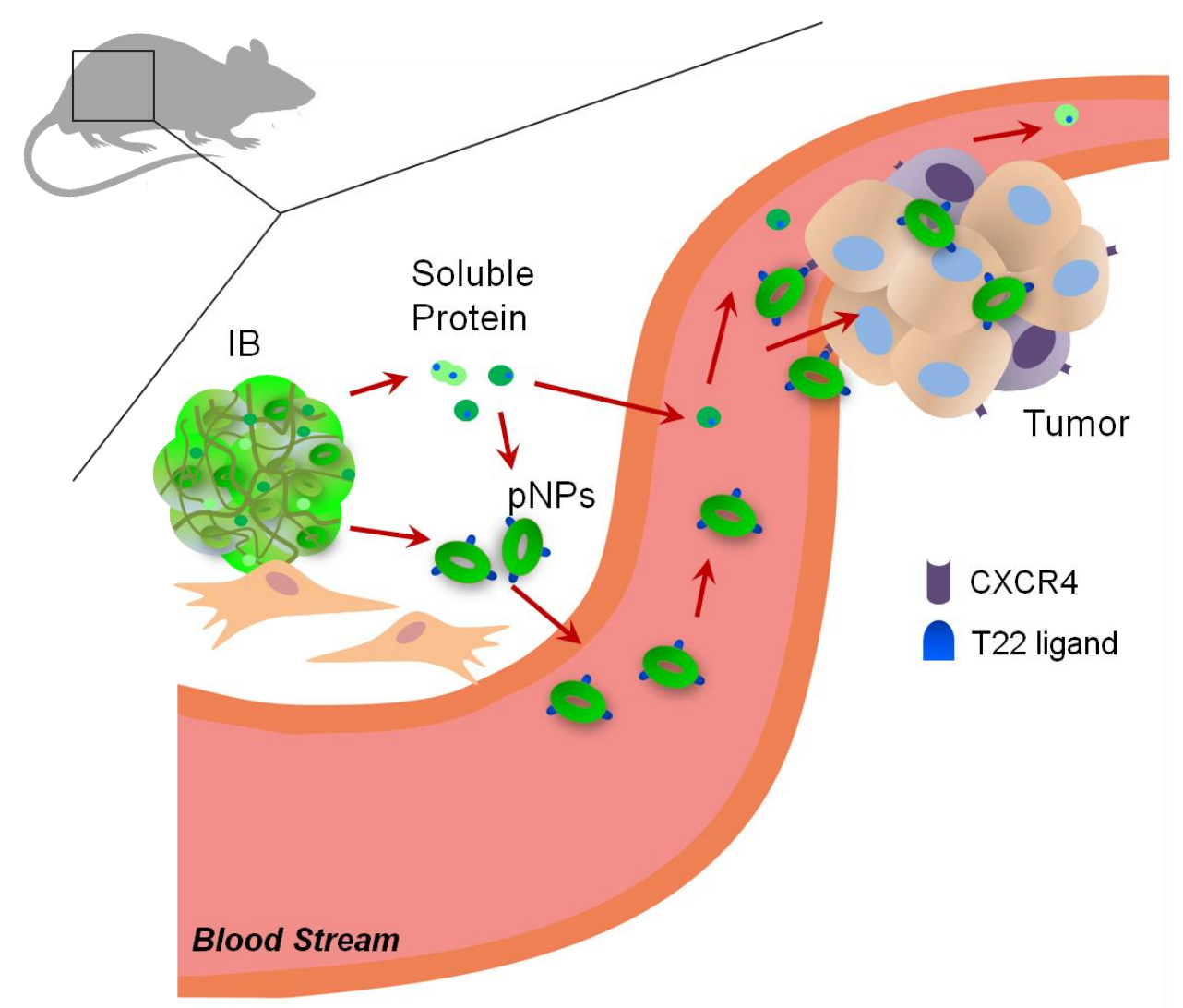

Figure 7. Scheme of the pathway followed by targeted T22-GFP-H6 IBs upon subcutaneous implantation. Subcutaneously injected T22-GFP-H6 IBs release pNPs or monomeric T22-GFP-H6 able to cross into the blood stream and accumulate in distant CXCR4+ tumors. Nanostructured protein would be easily internalized by $\mathrm{CXCR} 4{ }^{+}$cells and avoid renal clearance.

The material released from these insoluble reservoirs was able to penetrate the surrounding tissue at the injection site and implied a sustained concentration of the potentially therapeutic agent in blood. This provided a constant income with maintained levels and long lasting effect instead of the usual oscillatory levels with punctual high concentration peaks occurring when NPs or other soluble drug are administrated intravenously [42]. In this regard, T22-GFP-H6 pNPs have been previously described as a promising DDS for colorectal cancer treatment [18]. In addition, it has been shown that T22-GFP-H6 pNPs successfully accumulate in $\mathrm{CXCR}^{+}$tumors after $24 \mathrm{~h}$ upon intravenous administration but their presence was almost non-existent at $48 \mathrm{~h}[18,8]$. These results contrast with our data showing a significantly longer half-life of pNPs within the body when implanted subcutaneously packed as IBs. In this last case, fluorescence in blood and accumulation in tumors were detected after 10 days post subcutaneous injection. Nevertheless, biodistribution and intracellular T22 driven targeting of pNPs 
released from IBs and previous studies using pNPs self-assembled from T22-GFP-H6 soluble protein showed very similar patterns. In both cases notable accumulation in the targeted tumor and little off target detection of pNP have been observed indicating that pNPs released from IBs are fully functional in the in vivo context.

The pharmacokinetic/ pharmacodynamic (PK/PD) behavior of each novel therapeutic protein SC injected as IBs may depend on the IBs release kinetics of soluble pNPs from the hypodermis to enter the bloodstream and also on the capacity of the released and targeted pNPs to penetrate tumor tissue and internalize in target cancer cells (in our case CXCR4 ${ }^{+}$cancer cells), through receptor-dependent endocytosis. This will require specific studies devoted to demonstrate the reproducibility of its kinetic behavior and the optimization in a trial-and-error approach to obtain the appropriate mechanical properties of the DDS that fulfill the prospected therapeutic application.

In contrast, although the fluorescent signal in tumors was also detectable for VP1-GFP samples there was no accumulation along the time. This suggests punctual increased concentration of VP1-GFP at tumor site probably by EPR effect but a lack of internalization of the protein into tumor cells. These results are supported by the immunofluorescence images showing faint and diffuse signal for the VP1-GFP samples in tumor after $5 \mathrm{~d}$ upon IBs injection.

Although pNPs release have been demonstrated in vitro, protein release in a monomeric form cannot be completely discarded. However, our results indicate that an important amount of the released material is in form of already assembled pNPs or self-assembled in the microenvironment at the implantation site. An elegant study performed by Cespedes and co-workers has recently described how to determine pNP architectural stability in vivo by the analysis of renal clearance [30]. This study showed how monomeric protein, smaller than $7 \mathrm{~nm}$, is rapidly cleared through renal filtration while bigger entities such pNPs avoid renal filtration enhancing their blood circulation time and accumulation in the target tissues. Additional studies have shown also a strong influence of nanoparticle surface charge in renal filtration showing how negatively charged particles are better retained than the positively charged ones [43]. In this regard, T22-GFP-H6, when self-assembled in pNPs has been previously described as slightly negatively charged pNPs, z potential $=-17.2 \mathrm{mV}$, (unpublished data). These facts indicate that fluorescent signal observed in tumors for T22-GFP-H6 samples comes from nanostructured particles. In accordance, we observed at short times upon T22-GFP-H6 subcutaneous injection, some fluorescence in kidney that 
faded away at longer time points, while a diffuse but more stable signal along time was detected for VP1-GFP IBs. Nevertheless, T22-GFP-H6 signal observed in kidney for these samples appeared focused and exhibited notable levels of fluorescence. Monomeric protein is likely to be fast cleared away unable to render such fluorescence intensity. Thus, this concentrated fluorescence observed in kidney could be partially due to temporary retention of the pNP in the renal glomerule that eventually would enter the bloodstream again. In the case of VP1-GFP the lower and slower material release from the IB would be, as expected, mainly in form of monomeric protein since no significant accumulation is detected in either targeted tumors or off target tissues. In summary T22-GFP-H6 IBs can release protein in both pNPs form and in a lesser extent, monomeric form but the selfassembled fraction represents the predominant conformation of the released material at all the tested points.

Other biomaterials have been developed to provide a sustained release of the effector molecule from a biodegradable matrix or to be functionalized by the addition of biological components such as peptides [44,45]. However, their fabrication implies the production and conjugation of several components while in our approach we obtain a complex biomaterial in a single step by simple protein overexpression and deposition as insoluble protein clusters. IB suprastructure would act as a deck from where pNPs are released, resembling star fighters being launched from their base. These pNPs in turn can reach the bloodstream to be further distributed through the body providing a long lasting effect and an increased safety margin. In our case pNPs were targeted to $\mathrm{CXCR} 4^{+}$colorectal cancer tumors by the addition of T22 ligand in the modular protein. Noteworthy, this new approach in which pNPs are released from bigger entities such bacterial IBs could be adapted to an uncountable number of distinct diseases treatments by replacing both, the ligand that provides target specificity as well as the GFP reporter protein by other polypeptides with therapeutic activity as well as by adjusting production variables in order to tune physicochemical properties of the IBs. However, this optimization process is protein construct dependent and will need to be addressed in a trial-and-error based process to obtain the drug delivery system with the desired properties. Still, the use of biomaterials with bacterial origin can raise some concerns about the safety of the final product for implantable devices. In this regard, the development of new bacterial strains and protein production of IBs in GRAS organisms are addressing this issue $[46,47]$ with promising results. 


\section{Conclusion:}

In the present study we have generated novel smart biomaterials gathering most of the desirable features for implantable DDS, with cost effectiveness and simplicity in the biofabrication process. In this regard, single step fabricated IBs when injected subcutaneously rendered a long lasting release of targeted pNPs, able to enter to the blood stream and specifically target the tumor for as long as 10 days. We have described for the first time an approach for the fabrication of protein DDS based on protein deposition as IBs and their sustained release in form of fully functional targeted pNPs. This technology provides and stable source of targeted protein nanoparticles during long periods within the body with the action at distal points from the implantation site and pave the way for the appearance of new more efficient and less invasive treatments for a broad number of pathologies.

\section{Acknowledgments:}

We are indebted to Agencia Estatal de Investigación (AEI) and to Fondo Europeo de Desarrollo Regional (FEDER) (grant BIO2016-76063-R, AEI/FEDER, UE) and AGAUR (2017SGR-229) to AV, CIBER de Bioingeniería, Biomateriales y Nanomedicina (projects NANOREMOTE and VENOM4CANCER) to EV and AV respectively, Marató de TV3 foundation (TV32013-132031) and AGAUR (2014 PROD 00055) and CIBER (NanoMets3) to RM, ISCIII FIS to EV and RM (PI15/00272, PI15/00378, PIE15/00028) for funding our research on protein-based therapeutics. Protein production has been partially performed by the ICTS "NANBIOSIS", more specifically by the Protein Production Platform of CIBER in Bioengineering, Biomaterials \& Nanomedicine (CIBER-BBN)/ IBB, at the UAB SepBioES scientific-technical service (http://www.nanbiosis.es/unit/u1-protein-productionplatform-ppp/), whereas the in vivo biodistribution assays were performed in the NANBIOSIS Nanotoxicology platform (http://www.nanbiosis.es/unit/u18-nanotoxicologyunit/). We are also indebted to Fran Cortes from the Cell Culture and Cytometry Units of the Servei de CultiusCel-lulars, Producció d'Anticossos i Citometria (SCAC), and to the Servei de Microscòpia at the UAB. AV received an ICREA ACADEMIA award. U.U received a Sara Borrell postdoctoral fellowship from ISCIII, MVC was supported by Miguel Servet contract from ISCIII, LSG was supported by predoctoral fellowship by AGAUR (2017FI_B100063), And JSF received and AECC postdoctoral fellowship. . 


\section{Reference List}

[1] Chabner, B. A. and Roberts, T. G., Jr. Timeline: Chemotherapy and the war on cancer, Nat.Rev.Cancer.5 (2005) 65-72.

[2] Links, M. and Brown, R. Clinical relevance of the molecular mechanisms of resistance to anti-cancer drugs, Expert.Rev Mol.Med.1999 (25-10-1999) 1-21.

[3] Vinogradov, S. and Wei, X. Cancer stem cells and drug resistance: the potential of nanomedicine, Nanomedicine.(Lond).7 (2012) 597-615.

[4] Perez-Herrero, E. and Fernandez-Medarde, A. Advanced targeted therapies in cancer: Drug nanocarriers, the future of chemotherapy, Eur.J.Pharm.Biopharm.93 (2015) 5279.

[5] Zhao, Z., Pelletier, E., Barber, B., Bhosle, M., Wang, S., Gao, S., and Klingman, D. Patterns of treatment with chemotherapy and monoclonal antibodies for metastatic colorectal cancer in Western Europe, Curr.Med.Res.Opin.28 (2012) 221-229.

[6] Torchilin, V. Tumor delivery of macromolecular drugs based on the EPR effect, Adv.Drug Deliv.Rev.63 (18-3-2011) 131-135.

[7] Peer, D., Karp, J. M., Hong, S., Farokhzad, O. C., Margalit, R., and Langer, R. Nanocarriers as an emerging platform for cancer therapy, Nat.Nanotechnol.2 (2007) 751-760.

[8] Unzueta, U., Cespedes, M. V., Ferrer-Miralles, N., Casanova, I., Cedano, J., Corchero, J. L., Domingo-Espin, J., Villaverde, A., Mangues, R., and Vazquez, E. Intracellular CXCR4(+) cell targeting with T22-empowered protein-only nanoparticles, Int.J.Nanomedicine.7 (2012) 4533-4544.

[9] Pesarrodona, M., Ferrer-Miralles, N., Unzueta, U., Gener, P., Tatkiewicz, W., Abasolo, I., Ratera, I., Veciana, J., Schwartz S Jr, Villaverde, A., and Vazquez, E. Intracellular targeting of CD44+ cells with self-assembling, protein only nanoparticles, Int.J.Pharm.473 (1-10-2014) 286-295. 
[10] Serna, N., Cespedes, M. V., Saccardo, P., Xu, Z., Unzueta, U., Alamo, P., Pesarrodona, M., Sanchez-Chardi, A., Roldan, M., Mangues, R., Vazquez, E., Villaverde, A., and Ferrer-Miralles, N. Rational engineering of single-chain polypeptides into protein-only, BBB-targeted nanoparticles, Nanomedicine.12 (2016) 1241-1251.

[11] Lee, J. J., Kang, J. A., Ryu, Y., Han, S. S., Nam, Y. R., Rho, J. K., Choi, D. S., Kang, S. W., Lee, D. E., and Kim, H. S. Genetically engineered and self-assembled oncolytic protein nanoparticles for targeted cancer therapy, Biomaterials.120 (2017) 22-31.

[12] Murakami, T., Zhang, T. Y., Koyanagi, Y., Tanaka, Y., Kim, J., Suzuki, Y., Minoguchi, S., Tamamura, H., Waki, M., Matsumoto, A., Fujii, N., Shida, H., Hoxie, J. A., Peiper, S. C., and Yamamoto, N. Inhibitory mechanism of the CXCR4 antagonist T22 against human immunodeficiency virus type 1 infection, J.Virol.73 (1999) 7489-7496.

[13] Doranz, B. J., Filion, L. G., Diaz-Mitoma, F., Sitar, D. S., Sahai, J., Baribaud, F., Orsini, M. J., Benovic, J. L., Cameron, W., and Doms, R. W. Safe use of the CXCR4 inhibitor ALX40-4C in humans, AIDS Res.Hum.Retroviruses. 17 (10-4-2001) 475-486.

[14] Doranz, B. J., Grovit-Ferbas, K., Sharron, M. P., Mao, S. H., Goetz, M. B., Daar, E. S., Doms, R. W., and O'Brien, W. A. A small-molecule inhibitor directed against the chemokine receptor CXCR4 prevents its use as an HIV-1 coreceptor, J Exp.Med.186 (20-10-1997) 1395-1400.

[15] Zhao, H., Guo, L., Zhao, H., Zhao, J., Weng, H., and Zhao, B. CXCR4 overexpression and survival in cancer: a system review and meta-analysis, Oncotarget. 6 (10-3-2015) 5022-5040.

[16] Fischer, T., Nagel, F., Jacobs, S., Stumm, R., and Schulz, S. Reassessment of CXCR4 chemokine receptor expression in human normal and neoplastic tissues using the novel rabbit monoclonal antibody UMB-2, PLoS.One.3 (2008) e4069-

[17] Unzueta, U., Ferrer-Miralles, N., Cedano, J., Zikung, X., Pesarrodona, M., Saccardo, P., Garcia-Fruitos, E., Domingo-Espin, J., Kumar, P., Gupta, K. C., Mangues, R., Villaverde, A., and Vazquez, E. Non-amyloidogenic peptide tags for the regulatable self-assembling of protein-only nanoparticles, Biomaterials.33 (2012) 8714-8722. 
[18] Cespedes, M. V., Unzueta, U., Alamo, P., Gallardo, A., Sala, R., Casanova, I., Pavon, M. A., Mangues, M. A., Trias, M., Lopez-Pousa, A., Villaverde, A., Vazquez, E., and Mangues, R. Cancer-specific uptake of a liganded protein nanocarrier targeting aggressive CXCR4+ colorectal cancer models, Nanomedicine.12 (2016) 1987-1996.

[19] Seras-Franzoso, J., Sanchez-Chardi, A., Garcia-Fruitos, E., Vazquez, E., and Villaverde, A. Cellular uptake and intracellular fate of protein releasing bacterial amyloids in mammalian cells, Soft.Matter.12 (14-4-2016) 3451-3460.

[20] Unzueta, U., Seras-Franzoso, J., Cespedes, M. V., Saccardo, P., Cortes, F., Rueda, F., Garcia-Fruitos, E., Ferrer-Miralles, N., Mangues, R., Vazquez, E., and Villaverde, A. Engineering tumor cell targeting in nanoscale amyloidal materials, Nanotechnology.28 (6-1-2017) 015102-

[21] Cano-Garrido, O., Rodriguez-Carmona, E., Diez-Gil, C., Vazquez, E., Elizondo, E., Cubarsi, R., Seras-Franzoso, J., Corchero, J. L., Rinas, U., Ratera, I., Ventosa, N., Veciana, J., Villaverde, A., and Garcia-Fruitos, E. Supramolecular organization of protein-releasing functional amyloids solved in bacterial inclusion bodies, Acta Biomater.9 (2013) 6134-6142.

[22] Maji, S. K., Perrin, M. H., Sawaya, M. R., Jessberger, S., Vadodaria, K., Rissman, R. A., Singru, P. S., Nilsson, K. P., Simon, R., Schubert, D., Eisenberg, D., Rivier, J., Sawchenko, P., Vale, W., and Riek, R. Functional amyloids as natural storage of peptide hormones in pituitary secretory granules, Science.325 (17-7-2009) 328-332.

[23] Seras-Franzoso, J., Peebo, K., Garcia-Fruitos, E., Vazquez, E., Rinas, U., and Villaverde, A. Improving protein delivery of fibroblast growth factor-2 from bacterial inclusion bodies used as cell culture substrates, Acta Biomater.10 (2014) 1354-1359.

[24] Vazquez, E., Corchero, J. L., Burgueno, J. F., Seras-Franzoso, J., Kosoy, A., Bosser, R., Mendoza, R., Martinez-Lainez, J. M., Rinas, U., Fernandez, E., Ruiz-Avila, L., Garcia-Fruitos, E., and Villaverde, A. Functional inclusion bodies produced in bacteria as naturally occurring nanopills for advanced cell therapies, Adv.Mater.24 (3-4-2012) 1742-1747.

[25] Torrealba, D., Parra, D., Seras-Franzoso, J., Vallejos-Vidal, E., Yero, D., Gibert, I., Villaverde, A., Garcia-Fruitos, E., and Roher, N. Nanostructured recombinant 
cytokines: A highly stable alternative to short-lived prophylactics, Biomaterials.107 (2016) 102-114.

[26] Cespedes, M. V., Fernandez, Y., Unzueta, U., Mendoza, R., Seras-Franzoso, J., Sanchez-Chardi, A., Alamo, P., Toledo-Rubio, V., Ferrer-Miralles, N., Vazquez, E., Schwartz, S., Abasolo, I., Corchero, J. L., Mangues, R., and Villaverde, A. Bacterial mimetics of endocrine secretory granules as immobilized in vivo depots for functional protein drugs, Sci.Rep.6 (24-10-2016) 35765-

[27] Thomas, J. G. and Baneyx, F. Roles of the Escherichia coli small heat shock proteins IbpA and IbpB in thermal stress management: comparison with $\mathrm{ClpA}, \mathrm{ClpB}$, and HtpG In vivo, J.Bacteriol.180 (1998) 5165-5172.

[28] Richard, J. P., Melikov, K., Vives, E., Ramos, C., Verbeure, B., Gait, M. J., Chernomordik, L. V., and Lebleu, B. Cell-penetrating peptides. A reevaluation of the mechanism of cellular uptake, J.Biol.Chem.278 (3-1-2003) 585-590.

[29] Rueda, F., Cespedes, M. V., Conchillo-Sole, O., Sanchez-Chardi, A., SerasFranzoso, J., Cubarsi, R., Gallardo, A., Pesarrodona, M., Ferrer-Miralles, N., Daura, X., Vazquez, E., Garcia-Fruitos, E., Mangues, R., Unzueta, U., and Villaverde, A. Bottom-Up Instructive Quality Control in the Biofabrication of Smart Protein Materials, Adv.Mater.27 (16-12-2015) 7816-7822.

[30] Cespedes, M. V., Unzueta, U., Tatkiewicz, W., Sanchez-Chardi, A., Conchillo-Sole, O., Alamo, P., Xu, Z., Casanova, I., Corchero, J. L., Pesarrodona, M., Cedano, J., Daura, X., Ratera, I., Veciana, J., Ferrer-Miralles, N., Vazquez, E., Villaverde, A., and Mangues, R. In vivo architectonic stability of fully de novo designed protein-only nanoparticles, ACS Nano.8 (27-5-2014) 4166-4176.

[31] Garcia-Fruitos, E., Vazquez, E., Diez-Gil, C., Corchero, J. L., Seras-Franzoso, J., Ratera, I., Veciana, J., and Villaverde, A. Bacterial inclusion bodies: making gold from waste, Trends Biotechnol.30 (2012) 65-70.

[32] Rinas, U., Garcia-Fruitos, E., Corchero, J. L., Vazquez, E., Seras-Franzoso, J., and Villaverde, A. Bacterial Inclusion Bodies: Discovering Their Better Half, Trends Biochem.Sci.26-2-2017) 
[33] Rodriguez-Cabello, J. C., Arias, F. J., Rodrigo, M. A., and Girotti, A. Elastin-like polypeptides in drug delivery, Adv.Drug Deliv.Rev.97 (1-2-2016) 85-100.

[34] Vazquez, E., Roldan, M., Diez-Gil, C., Unzueta, U., Domingo-Espin, J., Cedano, J., Conchillo, O., Ratera, I., Veciana, J., Daura, X., Ferrer-Miralles, N., and Villaverde, A. Protein nanodisk assembling and intracellular trafficking powered by an arginine-rich (R9) peptide, Nanomedicine.(Lond).5 (2010) 259-268.

[35] Sanchez-Garcia, L., Serna, N., Alamo, P., Sala, R., Cespedes, M. V., Roldan, M., Sanchez-Chardi, A., Unzueta, U., Casanova, I., Mangues, R., Vazquez, E., and Villaverde, A. Self-assembling toxin-based nanoparticles as self-delivered antitumoral drugs, J.Control Release.274 (28-3-2018) 81-92.

[36] Serna, N., Céspedes, MV., Sánchez-García L., Unzueta,U., Sala, R., SánchezChardi, A., Cortés, F., Ferrer-Miralles, N., Mangues, R., Vázquez, E., and Villaverde, A. Peptide-Based Nanostructured Materials with Intrinsic Proapoptotic Activities in CXCR4+ Solid Tumors, Advanced Functional Materials.27 (2017) 1700919-

[37] Doglia, S. M., Ami, D., Natalello, A., Gatti-Lafranconi, P., and Lotti, M. Fourier transform infrared spectroscopy analysis of the conformational quality of recombinant proteins within inclusion bodies, Biotechnol.J.3 (2008) 193-201.

[38] Carrio, M. M. and Villaverde, A. Protein aggregation as bacterial inclusion bodies is reversible, FEBS Lett.489 (26-1-2001) 29-33.

[39] Peternel, S. and Komel, R. Active Protein Aggregates Produced in Escherichia coli, Int.J.Mol.Sci.12 (2011) 8275-8287.

[40] Garcia-Fruitos, E., Seras-Franzoso, J., Vazquez, E., and Villaverde, A. Tunable geometry of bacterial inclusion bodies as substrate materials for tissue engineering, Nanotechnology.21 (21-5-2010) 205101-

[41] Diez-Gil, C., Krabbenborg, S., Garcia-Fruitos, E., Vazquez, E., Rodriguez-Carmona, E., Ratera, I., Ventosa, N., Seras-Franzoso, J., Cano-Garrido, O., Ferrer-Miralles, N., Villaverde, A., and Veciana, J. The nanoscale properties of bacterial inclusion bodies and their effect on mammalian cell proliferation, Biomaterials.31 (2010) 5805-5812. 
[42] Parveen, S. and Sahoo, S. K. Long circulating chitosan/PEG blended PLGA nanoparticle for tumor drug delivery, Eur.J.Pharmacol.670 (30-11-2011) 372-383.

[43] Liang, X., Wang, H., Zhu, Y., Zhang, R., Cogger, V. C., Liu, X., Xu, Z. P., Grice, J. E., and Roberts, M. S. Short- and Long-Term Tracking of Anionic Ultrasmall Nanoparticles in Kidney, ACS Nano.10 (26-1-2016) 387-395.

[44] Makwana, H., Mastrotto, F., Magnusson, J. P., Sleep, D., Hay, J., Nicholls, K. J., Allen, S., and Alexander, C. Engineered Polymer-Transferrin Conjugates as SelfAssembling Targeted Drug Delivery Systems, Biomacromolecules.18 (8-5-2017) 1532-1543.

[45] Algar, W. R., Prasuhn, D. E., Stewart, M. H., Jennings, T. L., Blanco-Canosa, J. B., Dawson, P. E., and Medintz, I. L. The controlled display of biomolecules on nanoparticles: a challenge suited to bioorthogonal chemistry, Bioconjug.Chem.22 (18-5-2011) 825-858.

[46] Rueda, F., Cano-Garrido, O., Mamat, U., Wilke, K., Seras-Franzoso, J., GarciaFruitos, E., and Villaverde, A. Production of functional inclusion bodies in endotoxinfree Escherichia coli, Appl.Microbiol.Biotechnol.17-8-2014)

[47] Cano-Garrido, O., Cespedes, M. V., Unzueta, U., Saccardo, P., Roldan, M., SanchezChardi, A., Cubarsi, R., Vazquez, E., Mangues, R., Garcia-Fruitos, E., and Villaverde, A. CXCR4(+)-targeted protein nanoparticles produced in the food-grade bacterium Lactococcus lactis, Nanomedicine.(Lond).11 (2016) 2387-2398. 